\title{
CARCINOMA ESPINOCELULAR DE GENGIVA: ANÁLISE DAS IMAGENS DE SETE CASOS*
}

\author{
Ricardo Pires de Souza ${ }^{1}$, Paulo de Tarso Barbosa Moreira ${ }^{2}$, Ademar José de Oliveira \\ Paes Junior ${ }^{3}$, Mario C. Pacheco Neto ${ }^{2}$, Aldemir Humberto Soares ${ }^{4}$, Abrão Rapoport ${ }^{5}$
}

\begin{abstract}
Resumo Os autores estudaram sete casos de carcinoma de gengiva atendidos no Serviço de Cirurgia de Cabeça e Pescoço e Otorrinolaringologia e no Serviço de Diagnóstico por Imagem do Complexo Hospitalar Heliópolis, São Paulo, SP, entre 1985 e 1996. Todos os casos eram carcinomas do tipo espinocelular. Os sete pacientes eram do sexo masculino (100\%), com idade variando entre 48 e 72 anos (média de 57 anos). Exame de tomografia computadorizada foi realizado em seis $(85,6 \%)$ dos sete pacientes. Quatro pacientes $(57,1 \%)$ eram não tratados na ocasião do exame de imagem e três pacientes $(42,8 \%)$ já tinham tido algum tipo de tratamento (cirurgia ou radioterapia). Além disso, os autores analisaram o local primário e as extensões locais para a mandíbula $(5 / 7$ casos; $71,4 \%)$, para o soalho da boca $(3 / 7$ casos; $42,8 \%$ ), para o soalho do seio maxilar ( $1 / 7$ casos; $14,2 \%$ ) e para o trígono retromolar (1/7 casos; $14,2 \%)$. Linfonodos metastáticos foram observados em cinco pacientes $(71,4 \%)$. Biópsia e exame histopatológico confirmaram todos os casos. Confrontação com achados cirúrgicos foi possível em cinco casos $(71,4 \%)$.

Unitermos: Gengiva - carcinomas; Tumores malignos; Gengiva - tomografia computadorizada.
\end{abstract}

Abstract Gingival squamous cell carcinoma: imaging analysis of seven patients.

The authors studied seven patients with gingival carcinoma attended at the Head and Neck Surgery and Otorrhinolaryngology Service and the Diagnostic Imaging Service of "Complexo Hospitalar Heliópolis", São Paulo, SP, Brazil, between 1985 and 1996. Squamous cell type carcinomas were identified in all cases. All patients were male $(100 \%)$ aged $48-72$ years. Computed tomography was performed in six patients $(85.6 \%)$. Four patients $(57.1 \%)$ had not received any treatment before imaging examination whereas three patients $(42.8 \%)$ had already been submitted to surgery or radiotherapy. The authors analyzed the primary site of the tumor and its extension to the mandible (5/7 cases; $71.4 \%)$, the floor of the mouth $(3 / 7$ cases; $42.8 \%)$, the floor of the maxillary sinus $(1 / 7$ cases; $14.2 \%)$ and the retromolar trigonum (1/7 cases; $14.2 \%)$. Metastatic lymph nodes were observed in five patients $(71.4 \%)$. Diagnosis was confirmed by biopsy and histopathological examination in all cases. Comparison with surgical findings was possible in five cases (71.4\%). Key words: Gingiva - carcinomas; Malignant tumors; Gingiva - computed tomography.

\section{INTRODUÇÃO}

A gengiva é a mucosa que reveste os segmentos medianos e laterais da mandíbula e maxila. O sulco gengivovestibular é uma localização comum do carcinoma espinocelular (CEC) da cavidade oral. Além disso, há o trígono retromolar, onde o CEC também comumente surge $\mathrm{e}^{(\mathbf{1})}$.

* Trabalho realizado no Complexo Hospitalar Heliópolis, São Paulo, SP.

1. Diretor do Serviço de Diagnóstico por Imagem do Complexo Hospitalar Heliópolis.

2. Alunos do Curso de Pós-Graduação em Ciências da Saúde do Complexo Hospitalar Heliópolis.

3. Médico Residente do Serviço de Diagnóstico por Imagem do Complexo Hospitalar Heliópolis.

4. Diretor do Serviço de Diagnóstico por Imagem do Hospital do Servidor Público Estadual de São Paulo.

5. Coordenador do Curso de Pós-Graduação em Ciências da Saúde do Complexo Hospitalar Heliópolis.

Endereço para correspondência: Dr. Ricardo Pires de Souza. Complexo Hospitalar Heliópolis. Rua Cônego Xavier, 276, 10 andar. São Paulo, SP, 04231-030.E-mail: ricapires@ig.com.br

Recebido para publicação em 10/7/2002. Aceito, após revisão, em 18/3/2003.
A determinação de invasão óssea em carcinomas orais é um parâmetro importante para planejar o tratamento ${ }^{(2)}$.

\section{MATERIAIS E MÉTODOS}

Os autores estudaram sete casos de carcinoma de gengiva atendidos nos Serviços de Cirurgia de Cabeça e Pescoço e Otorrinolaringologia e de Diagnóstico por Imagem do Complexo Hospitalar Heliópolis, São Paulo, SP, entre 1985 e 1996.

Os sete pacientes eram do sexo masculino $(100,0 \%)$, com idade variando entre 48 e 72 anos (média de 57 anos). Todos os pacientes tinham história de tabagismo e consumo de álcool. Dos sete casos de carcinoma de gengiva, cinco localizavam-se na gengiva inferior $(71,4 \%)$ e dois situavam-se na gengiva superior $(28,4 \%)$.

Todos os casos eram de CEC. Exame de tomografia computadorizada (TC) foi rea- lizado em seis pacientes $(85,6 \%)$. Estes pacientes foram submetidos à TC com contraste iodado (iohexol $300 \mathrm{mg} / \mathrm{ml}$ ).

As varreduras tomográficas obtiveram cortes axiais e coronais com $5 \mathrm{~mm}$ de espessura e incremento, em equipamento de terceira geração. No momento do exame de imagem, quatro pacientes $(57,1 \%)$ eram não tratados e três $(42,8 \%)$ já tinham tido algum tipo de tratamento (cirurgia ou radioterapia). As imagens foram analisadas quanto ao sítio primário e extensão local dos tumores e presença de linfonodomegalias, por um experiente radiologista de cabeça e pescoço.

\section{RESULTADOS}

Em cinco casos $(71,4 \%)$ observou-se extensão dos tumores para a mandíbula, em três casos $(42,8 \%)$ para o soalho da boca, em um caso $(14,2 \%)$ para o soalho 


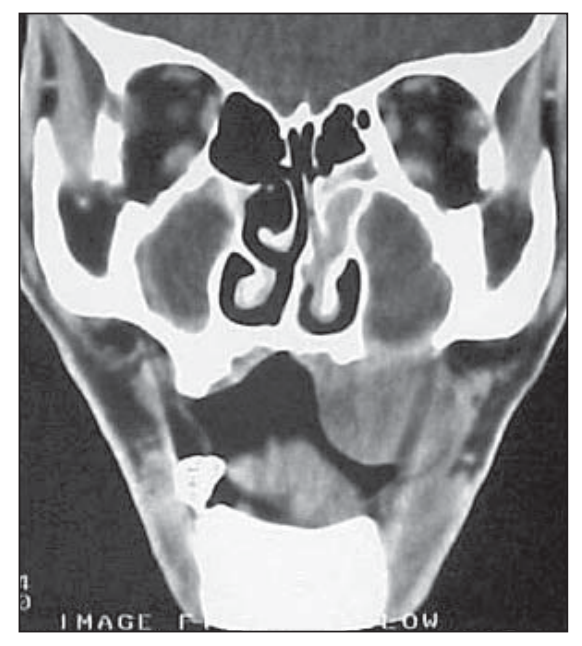

Figura 1. Corte coronal de tomografia computadorizada, janela de partes moles. Massa com densidade de partes moles envolvendo a borda alveolar da maxila esquerda, com descontinuidade da cuba do seio maxilar. Presença de secreções hipodensas em ambos os seios maxilares.

do seio maxilar e em um caso $(14,2 \%)$ para a região do trígono retromolar.

Todos os carcinomas de gengiva invadiam a mandíbula ou o soalho da boca (Tabela 1). Cinqüenta por cento dos carcinomas de gengiva superior envolviam o seio maxilar e os outros $50 \%$ envolviam o trígono retromolar. Linfonodomegalias foram observadas em cinco pacientes $(71,4 \%)$ (Tabela 2).

Biópsia com exame histopatológico confirmaram todos os casos. Confrontação com achados cirúrgicos foi possível em cinco casos $(71,4 \%)$.

\section{DISCUSSÃO}

Aproximadamente $91 \%$ dos carcinomas da cavidade oral são do tipo CEC. Esta neoplasia é agressiva e normalmente espalha-se através de invasão direta e pelos canais linfáticos ${ }^{(\mathbf{3})}$.

Foi observada associação significante entre o CEC de gengiva com o tabagismo e com consumo de álcool. Em uma revisão retrospectiva, Overholt et al. ${ }^{(\mathbf{4})}$ relataram que $80 \%$ dos pacientes com carcinoma de gengiva usavam tabaco e $47 \%$ consumiam álcool. Na presente série todos os pacientes eram usuários de tabaco e de álcool.

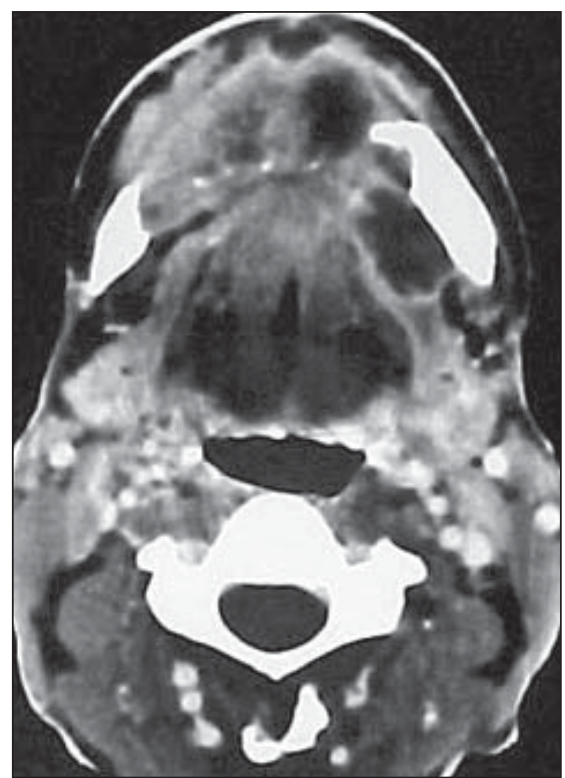

Figura 2. Corte axial de tomografia computadorizada, janela de partes moles. Massa heterogênea envolvendo a região mentoniana da mandíbula.

Tabela 1 Local primário $\times$ extensões.

\begin{tabular}{|l|c|c|}
\hline Extensão & $\begin{array}{c}\text { Gengiva } \\
\text { inferior }\end{array}$ & $\begin{array}{c}\text { Gengiva } \\
\text { superior }\end{array}$ \\
\hline Mandíbula & 5 & 0 \\
Soalho da boca & 3 & 0 \\
Seio maxilar & 0 & 1 \\
Trígono retromolar & 0 & 1 \\
\hline
\end{tabular}

Tabela 2 Linfonodos metastáticos $\times$ invasão óssea.

\begin{tabular}{|l|c|c|}
\hline & $\begin{array}{c}\text { Linfonodos } \\
\text { metastáticos }\end{array}$ & $\begin{array}{c}\text { Nenhum } \\
\text { linfonodo }\end{array}$ \\
\hline Invasão óssea & 5 & 2 \\
Sem invasão óssea & 0 & 0 \\
\hline
\end{tabular}

Alguns investigadores sugerem que trauma de alvéolo dentário durante extração na região da lesão primária possa conduzir a um aumento de risco de recidiva local ${ }^{(5)}$. Em nossa revisão não verificamos esta relação entre trauma ou extração dental no local primário e recidiva.

A identificação de invasão da mandíbula pelo câncer de cavidade oral é importante para planejar o tratamento.

Overholt et al. ${ }^{(4)}$ acharam envolvimento ósseo em $49 \%$ dos pacientes com carcinoma de gengiva inferior. Nossa taxa de invasão de mandíbula por CEC foi de 71,4\%.

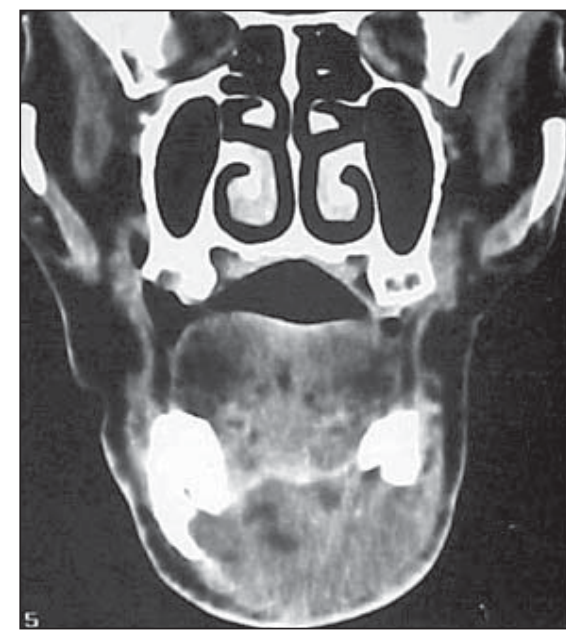

Figura 3. Corte coronal de tomografia computadorizada, janela de partes moles. Massa heterogênea envolvendo a região mentoniana da mandíbula. Aspecto semelhante ao da Figura 2.

Panagopoulas ${ }^{(\mathbf{6})}$ relatou erosão tumoral de mandíbula em $25 \%$ dos seus pacientes e demonstrou uma alta freqüência microscópica de invasão de osso com carcinoma gengival; observou, ainda, que a radiografia convencional não foi útil na identificação dos tumores que invadem osso, considerando que houve alta taxa de falso-positivos $(50 \%)$ para a série de radiografias convencionais de mandíbula.

A ressecção cirúrgica é o tratamento de escolha. Estudos tendem a confirmar a vantagem da ressecção modificada do pescoço (ressecção do osso adjacente) em pacientes selecionados adequadamente $e^{(7)}$.

Embora a invasão do osso adjacente influencie a sobrevida dos pacientes acometidos pela doença, o tamanho do tumor primário deve ser o determinante para indicar o tratamento apropriado. O grau de destruição de osso demonstrada à TC tem correlação com o verificado na cirurgia ou pelo exame anatomopatológico.

Araki et al. ${ }^{(\mathbf{8})}$ relataram que a sensibilidade, a especificidade e a precisão da TC para invasão de mucosa bucal foram de $64 \%$, $89 \%$ e $75 \%$, respectivamente. Para invasão do seio maxilar a TC apresentou baixa especificidade, mas alta sensibilidade, porque achados de TC sugestivos de 
destruição do soalho do seio maxilar não são sempre consistentes com invasão do seio maxilar.

O estudo por TC tem limitações específicas com respeito à avaliação de pacientes com carcinoma intra-oral. Primeiro, restaurações metálicas nos dentes podem produzir artefatos suficientes para impossibilitar a avaliação precisa dos tecidos moles e a extensão óssea da doença. Segundo, o tomógrafo computadorizado não pode diagnosticar com segurança a extensão da doença de tecidos moles se uma biópsia foi previamente realizada ${ }^{(9)}$.

A ressonância magnética (RM) é superior à TC na avaliação do envolvimento da mandíbula ${ }^{(2,10-12)}$, incluindo determinação de envolvimento do córtex e avaliação da invasão da medula óssea. A maioria das vantagens da RM deve-se à melhor demonstração dos tecidos moles com esta técnica e também à melhor distinção entre a medula óssea e o córtex. Restaurações dentárias praticamente não determinam artefatos nas imagens de $\mathrm{RM}^{(\mathbf{1 0 )}}$. Doença cervical metastática e envolvimento de mandíbula por CEC oral não apresentam correlação significativa (embora o número de casos seja muito pequeno para qualquer conclusão) ${ }^{(3)}$. Em nosso estudo, dos cinco pacientes com metástase para linfonodos, três $(60 \%)$ apresentavam invasão óssea da mandíbula. No entanto, dos cinco pacientes que apresentavam invasão óssea mandibular, dois (40\%) não desenvolveram metástase para linfonodos.

Invasão de osso pode ser demonstrada em TC e radiografias convencionais, mas reação periosteal isolada somente pode ser detectada por cintilografia ${ }^{(13)}$.

\section{REFERÊNCIAS}

1. Smoker WRK. Oral cavity. In: Som PM, Curtin HD, eds. 3rd ed. Head and neck imaging. St. Louis, MO: Mosby-Year Book, 1996.

2. Weisman RA, Kimmelman CP. Bone scanning in the assessment of mandibular invasion by oral cavity carcinomas. Laryngoscope 1982;92:1-4.

3. Gilbert S, Tzadik A, Leonard G. Mandibular involvement by oral squamous cell carcinoma. Laryngoscope 1986;96:96-101.

4. Overholt SM, Eicher SA, Wolf P, Weber RS. Prognostic factors affecting outcome in lower gingival carcinoma. Laryngoscope 1996;106:1335-9.

5. Soo KC, Spiro RH, King W, Harvey W, Strong EW. Squamous carcinoma of the gums. Am J Surg 1988;156:281-5.
6. Panagopoulas AP. Involvement in maxillofacial cancer. Am J Surg 1959;98:890-903.

7. Gomez D, Faucher A, Picot V, et al. Outcome of squamous cell carcinoma of the gingiva: a followup study of 83 cases. J Craniomaxillofac Surg 2000;28:331-5.

8. Araki K, Ariji E, Shimizu M, et al. Computed tomography of carcinoma of the upper gingiva and hard palate: correlation with the surgical and histopathological findings. Dentomaxillofac Radiol 1997;26:177-82.

9. Close LG, Merkel M, Burns DK, Schaefer SD. Computed tomography in the assessment of mandibular invasion by intraoral carcinoma. Ann Otol Rhinol Laryngol 1986;95:383-8.

10. Ator GA, Abemayor E, Lufkin RB, Hanafee WN, Ward PH. Evaluation of mandibular tumor invasion with magnetic resonance imaging. Arch Otolaryngol Head Neck Surg 1990;116:454-9.

11. Nallet E, Piekarski D, Bensimon JL, Ameline E, Barry B, Gebanno P. Apport de l'IRM et du scanner dans les cancers oro-buccopharyngés avec envahissement osseux. Ann Otolaryngol Chir Cervicofac 1999;116:263-9.

12. Luyk NH, Laird EE, Ward-Booth P, Rankin D, Williams ED. The use of radionuclide bone scintigraphy to determine local spread of oral squamous cell carcinoma to mandible. J Maxillofac Surg 1986;14:93-8.

13. Brown JS, Griffith JF, Phelps PD, Browne RM. A comparison of different imaging modalities and direct inspection after periosteal stripping in predicting the invasion of the mandible by oral squamous cell carcinoma. Br J Oral Maxillofac Surg 1994;32:347-59. 